\title{
EFFECT OF LATERALIZED EPILEPTIC DISCHARGES ON THE THOUGHT FLOW
}

\author{
Paulo Bueno de Mendonça', Lucy Campos Piccinin', \\ Celso Medeiros Capucho ${ }^{3}$, Carlos José Reis de Campos ${ }^{4}$
}

\begin{abstract}
Purpose: Pauses in verbal expression of thought flow in patients with partial epilepsy was studied in order to achieve a best comprehension of brain interhemispheric influences. Method: We studied thirty nine patients with partial epileptic seizures and twenty four volunteers (control group). Free association of ideas was used as a method to stablish the thought flow, starting with a stimulus word (subject name) that must be followed by spontaneous and consecutive word-phrase. Patients were instructed to say any thought that came to their minds without any kind of censoring. Subject responses were recorded through a PC keyboard and time intervals (pauses) between each word-phrase were processed by a software developed for this purpose. Results: Time intervals reduction among associations in right lesional group were compared to left lesional, right non-lesional and control groups. An increase of associative time intervals was observed in the right non-lesional group compared to left non-lesional group. Conclusions: We suggest a possible inhibitory inter-hemispheric function of the right hemisphere modulating verbal expression of the thought flow. Considering the hypothesis of the inter-hemispheric inhibition by the right hemisphere on left hemisphere, we admit that in epileptic patients with right hemispheric lesion there is an attenuation of the inter-hemispheric inhibition and an increase in thought flow, whereas in patients without a lesion but a paroxysmal epileptic activity in right temporal lobe there is an exacerbation of this inhibitory function and consequent reduction in the thought flow.
\end{abstract}

KEY WORDS: partial epilepsy, free association, computerized psychological test, thought flow.

\begin{abstract}
Efeito de descargas epilépticas lateralizadas no fluxo do pensamento
RESUMO - Objetivo: Foram estudadas as pausas na expressão verbal do pensamento em pacientes com epilepsia parcial a fim de estabelecer uma melhor compreensão das influências interhemisféricas cerebrais. Método: foram estudados 39 pacientes com crises epilépticas parciais e 24 voluntários (grupo controle). A associação livre de idéias foi usada como método para estabelecer o fluxo do pensamento, partindo de uma palavra-frase (nome do indivíduo) que devia ser seguida por palavras-frase espontâneas e consecutivas. Os pacientes foram orientados para dizer qualquer pensamento que viesse as suas mentes, sem qualquer tipo de censura. As respostas individuais foram registradas por meio de um teclado de computador (PC) e os intervalos de tempo (pausas) entre cada palavra-frase foram processadas por um software especialmente desenvolvido. Resultados: Redução nos intervalos de tempo entre as associações encontrada no grupo lesional direito foi comparada aos grupos lesional esquerdo, não-lesional direito e controle. Um aumento nos intervalos de tempo das associações foi observado no grupo não lesional direito em relação ao grupo não-lesional esquerdo. Conclusões: Os resultado encontrados sugerem uma possível função inibitória do hemisfério direito modulando a expressão verbal do fluxo do pensamento. Considerando a hipótese da inibição inter-hemisférica pelo hemisfério direito sobre o hemisfério esquerdo, podemos admitir que em pacientes epilépticos com lesão hemisférica há uma atenuação da inibição inter-hemisférica e um aumento no fluxo do pensamento, enquanto que em pacientes sem lesão, porém com uma atividade epiléptica paroxística no lobo temporal direito há uma exacerbação desta função inibitória e consequente redução no fluxo do pensamento.
\end{abstract}

PALAVRAS-CHAVE: epilesia parcial, associação livre, teste psicológico computadorizado, fluxo do pensamento.

The flow of our thought depends on many circumstances once our organism has been subject to a large number of situations and, consequently, to a great number of stimuli, which, if they are not in- tensive enough to be distinguished on our conscience, must at least influence in the dynamic state of our nervous centers. Some of these stimuli come from the environment, others from our body; most

\footnotetext{
Federal University of São Paulo, São Paulo SP, Brazil (UNIFESP): ${ }^{1}$ Post-Graduation Student of Neuroscience, UNIFESP; ${ }^{2}$ Psychologist, Epilepsy Section of Neurology and Neurosurgery Department UNIFESP; ${ }^{3}$ Computer Programmer, Neurology and Neurosurgery Department UNIFESP; ${ }^{4}$ Associated Professor, MD, PhD, Neurology and Neurosurgery Department UNIFESP
}

Received 20 November 2000, received in final form February 2001. Accepted 13 February 2001. 
of them remain underneath the threshold of our conscience, being able to deliver new ideas, to modify the current course of thought or even to rise in normal or pathological dream ${ }^{1}$. During all life human beings develop a psycho-neural processing of sensations and perceptions in a way to allow storage in memory and later be brought to the conscience and processed in the absence of the original stimuli. We call this process symbolic thought. The symbolic thought enables human beings the capacity to reflect about everything that, somehow, is presented to their perception. Traditionally, the free association of ideas has been used as searching method to the contents of the mind. This method consists of stating indiscriminately all thoughts occurring to the mind, either spontaneously or triggered by a previously given stimulus (word, number, dream images or any another representation) ${ }^{2}$.

Jung ${ }^{3,4}$ using inductive words elaborated a test of association consisting of a list of words. When the inductive word is naturally associated with the induced word and related to one aggressive complex, the subject will try to avoid the induced and revealing word, but he or she will be invaded by the aggressive emotion and, there after, it will not occur to him or her any common word. He or she will be felt psychologically frozen. According to Bleuler, "In associative activity we have reflected all the past and present psychism, experiences and tendencies. Consequently, it points to all the psychic processes, that it is enough to decipher in order to know the inner man" 5 .

In this paper we use a verbal expression of "associative ideas flow" as an experimental paradigm to accomplish the "thought flow".

The human brain is formed by two hemispheres with relative symmetry. These hemispheres are linked together by a bridge of nervous fibres, called corpus callosum, making them function as if they were only one. However, there is an asymmetrical difference in the functions of these two hemispheres, which we call hemispheric dominance, that is a lateralization of certain functions, either in the left or right hemisphere. Due to corpus callosum, cerebral hemispheric function integrates verbal and image processing, in order that together they can communicate better than separately ${ }^{6}$. The studies of human cerebral dysfunction in patients with brain lesions, as consequence of CNS surgeries or skull traumas, help us to know the normal functioning of the brain.

For the study of hemispheric preferences in normal individuals, several approaches have been used, like the Sodic Amital Test (Wada Test). Brief mood disturbances have been related to the injection side of sodic amital. Left carotid artery injection has produced a short period of depression, while injection in the right side has produced euphoria. These results suggest that some degree of lateralization for the humor state exists in the human brain. Patient with left hemispheric lesion seems more concerned about symptoms, while patients with right hemispheric lesion usually show a pathological indifference to handicapped performance ${ }^{6}$.

Tests for evaluation of functional hemispheric asymmetry include visual perception (tachistoscopic stimulation), auditory perception (dichotic stimulation), which are used as noninvasive techniques ${ }^{7-9}$. These tests performed in individuals with corpus callosum section disclosed that conscious experiences only are related to activities of the dominant hemisphere for language and the most important discovery in patients with commissural sections is the unique and exclusive character of the dominant language hemisphere for the existence of the conscious experience ${ }^{10}$.

In normal individuals the activity of the non-dominant hemisphere reaches consciousness only after its transmission to the dominant language hemisphere, what occurs through the immense traffic of impulses in the corpus callosum ${ }^{10}$.

The purpose of this paper is to study the pause's duration in the verbal expression of the thought flow in patients with partial epilepsies in order to achieve a best comprehension of the brain inter hemispheric influences.

\section{METHOD}

\section{Casuistic}

1. Patients with epilepsy

The epilepsy group consisted of thirty-nine patients from São Paulo School of Medicine (UNIFESP-EPM), bearing partial epilepsy diagnosis.

To be include in this group all patients should have: over fifteen years old and under fifty years; partial epileptic seizures; recent skull image examinations (CT-Scan or Magnetic Resonance Images - MRI); very clear EEG localized discharges, but not frequent or continuous; one or two anti epileptic drugs (AED) at most, in therapeutic doses and without intoxication signs; Educational level over eighth grade.

Patients were excluded of this group in case they had: bilateral or extra-temporal lesion; alcohol or drug addition during a period of one year preceding the study; mental deficiency (I.Q. under 60); psychotic humor disease treated with neuroleptic or antidepressive drugs; progressive diseases. 
Epileptic group were classified again in two subgroups called Lesional and Non-Lesional.

Lesional Group - This group had evidences of CT-Scan and/or MRI structural lesions in temporal lobe and clear paroxysmal epileptic discharges in the same cerebral hemisphere.

These twenty patients were distributed according to lesion localization in the following subgroups:

- Right lesional group: ten patients with lesion in the right temporal lobe.

- Left lesional group: ten patients with lesion in the left temporal lobe.

- Non-Lesional Group - In this group we have nineteen patients without any evidence of structural brain lesion in CT-Scan and/or MRI, but with clear paroxysmal epileptic discharges in the interictal EEG. Right NonLesional Group: Ten cases with clear paroxysmal epileptic discharges on right temporal area in the interictal EEG. Left Non-Lesional Group: Nine cases with clear paroxysmal epileptic discharges on left temporal area in the interictal EEG.

\section{Control Group}

The Control Group included twenty and four volunteers, family relatives of patients, between fifteen and fifty years old, and without any previous neurological illness or epileptic seizures. Patients and volunteers agreed to participate of this study after being informed about its nature, according to an approval of the institutional review board.

\section{Test application}

Patients and volunteers underwent in one session the four series tests of free associations. Before test application patients or volunteers were informed that:

1. After to say a word and during one time period they must say everything coming to their mind, omitting nothing for more insignificant than it could seem;

2. All word-phrase spoke would be recorded trough a PC keyboard, so that later we could analyze them; it was explained that patients were not having to be worried about this, because there were not in test things as right/wrong or few/much;

3. Examples were given: "if the word said for me was beach, what it comes from your mind?". We waited some seconds and, if test subjects did not understand or associate anything, the applicator added, "to me it comes: water, sea, ship, ball, heat, holidays, etc... Did you understand?", after this example a new training was performed in order to assure the correct test comprehension.

Following this it was started the real four series of associations. The first one was started by the name of the subject. Second, third and fourth series were induced by words appeared in the first series of associations that presented the higher time intervals (pauses) between associations.
A software specially created for this computerized test (EPI-FLOW) added the time intervals between associations and when reaching 60 seconds the computer emitted a "bip" ending the serie. The explanation training and application time of the whole test (four series) were about 30 minutes for each individual.

The computer system was designed for recording thought flow (association of ideas) with the following objectives: to keep control of each individual subject data; to record subject associations in real time, through keyboard data entered by the applicator; to take the time interval between each word and its antecedent, subtracting the time of keyboard data entered; to calculate the average of these intervals of time and its standard deviation; to suggest, through the high interval of time between associations, signs of possible emotional freezing or thought flow reduction.

For the statistical analysis the Kruskal-Wallis Test for three or more independent samples with multiple comparisons was used ${ }^{11}$.

\section{RESULTS}

We observed in Table 1 a reduction of time intervals between the associations of the ideas in the right lesional group when compared to left lesional, right non-lesional and control groups.

We can also observe an increase of the time intervals between the associations of the ideas in the right non-lesional group when compared with the left non-lesional group.

\section{DISCUSSION}

The disorder of thought flow is a well-known phenomenon in psychiatry. "The inhibition of the thought is a symptom generally associated to the slowness of all the psychic functions. It is characterized by the reduction of the number of evoked representations and by the slowness of the thought flow. The patient with thought inhibition shows difficulty in understanding, hardly initiates a conversation, delays to pronounce words, thinks with great effort and delays to answer because nothing appears in his disturbed mind"12. It has been suggested that frequency and duration of the speech pauses in psychiatric patient can be matched to patient mood. The increase of frequency and duration (average frequency above 4.8 pauses/min and average duration above 1.5 second) points to depression; the reduction in average duration of the pauses (less than 1.15 second) points to mania state which, according to Friedman ${ }^{13,14}$, is regulate by the basal region of the right temporal lobe.

We prefer to think that some disturbances in psychic dynamism of epileptic patients are related to the 
Table 1. Free associative verbal time intervals in the Lesional, Non-Lesional Epileptic and Control groups.

\begin{tabular}{|c|c|c|c|c|c|c|}
\hline & \multicolumn{2}{|c|}{ Lesional } & \multicolumn{2}{|c|}{ Non-Lesional } & \multirow{2}{*}{\multicolumn{2}{|c|}{$\begin{array}{c}C \\
N=24\end{array}$}} \\
\hline & $\begin{array}{c}\mathrm{RL} \\
\mathrm{N}=10\end{array}$ & $\begin{array}{c}\mathrm{LL} \\
\mathrm{N}=10\end{array}$ & RNL & LNL & & \\
\hline & 0,54 & 0,79 & 0,66 & 0,57 & 0,73 & 2,42 \\
\hline & 0,57 & 0,82 & 0,86 & 0,61 & 0,78 & 2,47 \\
\hline & 0,59 & 0,92 & 0,92 & 0,77 & 0,66 & 1,95 \\
\hline & 0,64 & 0,94 & 1,45 & 0,79 & 0,61 & 1,33 \\
\hline & 0,65 & 1,28 & 2,05 & 0,81 & 1,04 & 4,07 \\
\hline & 0,78 & 1,62 & 5,85 & 1,22 & 0,66 & 2,09 \\
\hline & 0,89 & 1,70 & 6,00 & 1,45 & 0,63 & 1,69 \\
\hline & 1,15 & 2,90 & 6,00 & 3,40 & 0,59 & 1,17 \\
\hline & 1,32 & 4,24 & 8,96 & 5,26 & 0,65 & 1,85 \\
\hline & 1,62 & 5,00 & 10,34 & & 0,7 & 2,22 \\
\hline & & & & & 1,04 & 5,22 \\
\hline & & & & & 1,11 & 6,15 \\
\hline Median & 0,71 & 1,45 & 3,95 & 0,81 & & \\
\hline
\end{tabular}

Kruskal-Wallis Test - Hcalculated $=12,340$ (Significant) Hcritical: 9,488 (Alfa $=5 \%$ )

Test of Multiple Comparisons with significant differences

$\begin{array}{ll}R L \times L L & \text { Significant } p<0,05 \\ R L \times R N L & \text { Significant } p<0,05 \\ R L \times C & \text { Significant } p<0,05 \\ \text { RNL } x \text { LNL } & \text { Significant } p<0,05\end{array}$

Other significant differences between the epileptic groups (Lesional and Non-Lesional) and the Control group had not been found.

The numbers express intervals of time averages in seconds.

C, control group; RL, right lesional group; LL, left lesional group; RNL, right non-lesional group; LNL, left non-lesional group.

effect of interictal paroxysmal epileptic discharges, cerebral lesions, as well as psychodynamic influences.

Generalized or partial complex seizures interrupt cognitive functions and even subclinical epileptic discharges, without clinical symptomatology, seem to influence the cognition and motor responses ${ }^{15}$.

Patients with lesion or paroxysmal epileptic activity in the left temporal lobe show disturbances of speech production and understanding ${ }^{16-18}$. Patients with paroxysmal epileptic activity in the left temporal lobe show a worse performance in association tests than patients with paroxysmal epileptic activity in the right temporal lobe ${ }^{19}$. Left temporal lobe lesions can produce cognitive disturbances, mainly in speech production and understanding ${ }^{18}$. Patients with left temporal lobe paroxysmal epileptic activity show a low performance in neuropsychological tests for speech and language evaluation ${ }^{17}$.
Cauthen ${ }^{20}$ observed that age and intelligence quotient (IQ) do not influence the verbal fluency in normal individuals.

Our results show differences in right and left lesional and non-lesional groups. While the results of the lesional group agreed to literature regarding to the reduction of the verbal fluency in patients with lesion in the left hemisphere, the non-lesional group pointed to another direction, with associative flow slowness in patients with paroxysmal epileptic activity in right hemisphere (Table 1).

We compared our results of left hemisphere groups (lesional and non-lesional) with results of control group and we verified that time intervals decreased among associations in right lesional group compared to left lesional, right non-lesional and control groups. An increase of associative time intervals was observed in the right non-lesional group 
compared to left non-lesional group. The results indicate that cerebral lesion and paroxysmal epileptic activity in left hemisphere do not interfere with time intervals between associations.

We can explain our results considering that free association of ideas demands less patient cognitive performance or the thought flow express primordially emotional aspects that are more related to the functions of right cerebral hemisphere ${ }^{21-23}$.

Right cerebral hemisphere lesions seems to harm memory with emotional content and is associated with the inability of understanding facial expression of emotion and disturbs the expression of emotion by means of speech inflections ${ }^{21}$.

Right cerebral hemisphere plays a special role in experience, expression and discrimination of all emotions. However, alternative points of view consider that both cerebral hemispheres have an equivalent role in the emotion, but the kind of emotion expression of each side of the brain differs, the left hemisphere tends to euphoria and the right hemisphere tends to dysphoria. Patients with lesion in the left hemisphere show depressive-catastrophic reaction, whereas those with lesion in the right hemisphere present euphoric-complaisant reaction ${ }^{22}$. To these authors it is the lesion in one of the brain sides that induces disinhibition of the intact hemisphere. Tucker ${ }^{23}$ otherwise stated that left hemisphere would tend to depression and right hemisphere to the euphoria, because cortical damage could induce disinhibition of the ipsilateral limbic area, exaggerating the emotional expression. Charmam ${ }^{24}$ found greater activity of the right cerebral hemisphere in extro- verted individuals that presented a better left visual field (right hemisphere) performance in tachistoscopic verbal tasks, whereas introverted individuals showed a better performance in right visual field (left hemisphere).

By this way we can explain our results according to the lesion or the paroxysmal epileptic activity in right cerebral hemisphere.

It is not well established how local neuronal discharges interfere with the cognitive processing speed of epileptic patients ${ }^{15,25}$. Some hypotheses have been suggested to explain asymmetrical dysfunction of temporal lobes, including biochemical differences in cholinergic system of the temporal lobe ${ }^{26}$, neuroendocrinological dysfunction, particularly the hypothalamus-hypophyseal control of the secretion of gonadotrophines ${ }^{27}$ or even kindling effect in temporo-limbic areas ${ }^{28,29}$.

To explain our results we have considered the theory of inter-hemispheric inhibition, the result of reciprocal interaction (inhibitory or facilitatory nature) between both hemispheres. According to this theory the epileptic discharges in a cerebral hemisphere can inhibit functions of contralateral opposing hemisphere, due to continuous stimulation of contralateral structures ${ }^{30}$.

The improvement in linguistic performance in neuropsychological tests of patients with corpus callosum section suggests that the corpus callosum can propagate inhibitory information of the hemisphere with epileptic discharges to the normal hemisphere $^{31}$.

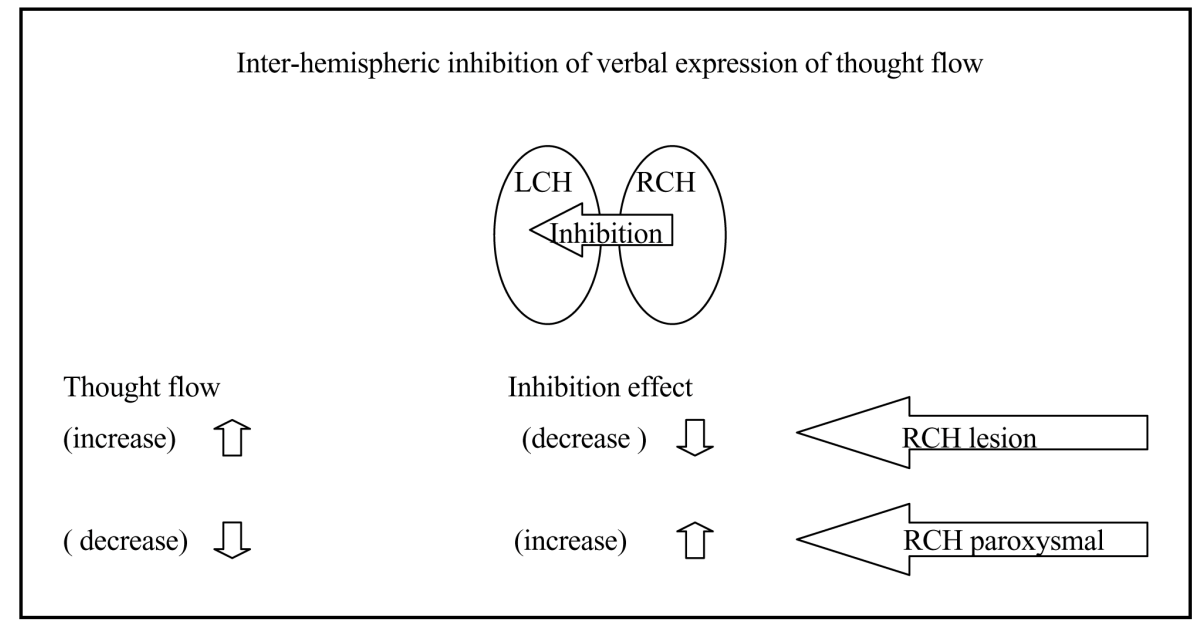

Fig 1. Graphical representation of the hypothesis in which the right cerebral hemisphere modulates the flow of the verbal expression of the thought, through the inter-hemispheric inhibition. $L C H$, left cerebral hemisphere; $R C H$, right cerebral hemisphere. 
Collard et al. ${ }^{32}$, using verbal dichotic tests in epileptic patients, observed after temporal lobectomy an improvement of the responses in the ipsilateral ear and suggest that paroxysmal activity produces an inhibitory influence in contralateral cortex function.

The hemispheric preference during dichotic stimulation in patients with partial epilepsy changes in the presence or absence of cerebral lesion. The "lesion effect" characterized by preference for the normal side, can be observed in patients with lesional partial epilepsy, and the "paradoxical effect", characterized by the hemispheric preference where is the EEG paroxysmal epileptic activity in non-lesional partial epilepsy ${ }^{33}$. This could be confirmed by evidences that cerebral lesion really shifts the hemispheric preference for the intact side, while in the absence of cerebral lesion, the side of hemispheric preference shifts to the side of paroxysmal epileptic activity in interictal EEG ${ }^{7,9}$.

Patient with partial epilepsy and right lateralized paroxysmal epileptic activity did not present hemispheric lateralization in tachistoscopic test (numerical stimuli) and Muszkat ${ }^{8}$ suggested that paroxysmal discharges in right cerebral hemisphere modify the left hemispheric preference for processing verbal stimuli (numerical).

Considering that right cerebral hemisphere can be responsible for understanding and expression of emotional life and that right hemisphere can inhibit functions of the left hemisphere, we suggest that right cerebral hemisphere is responsible for modulation of verbal expression of thought flow (Fig 1).

According to the theory of right hemispheric inhibition over left hemisphere, we can suggest that in epileptic patients with lesion in right hemisphere there is an attenuation of the inter-hemispheric inhibition and an increase in the thought flow. However, in non-lesional epileptic patients with clear focal paroxysmal epileptic activity in right temporal lobe there is an exacerbation of this inhibitory function and consequent reduction of thought flow (paradoxical effect). Thus, we can assume that the intensity of this inhibitory function is closely related with the modulation (increase or reduction) of the verbal expression of thought flow.

With regard to the computer use and the software EPI-FLOW, we can state that they had been of great help in this work, providing us the recording of associations and statistical processing of time intervals, between free verbal associations and it represents a useful method in follow-up of functional disturbances, like the cerebral processing of the thought flow.

\section{REFERENCES}

1. Claparede E. La associacion de las ideas. Trad. Domingos Barreto, Madrid: Daniel Jorro Editor, 1907.

2. Laplanche J, Pontalis JB. Psychoanalysis vocabulary. 9Ed. brasileira, trad. Pedro Tamen, São Paulo: Martins Fontes, 1986.

3. Jung CG. The psyche nature. Obras completas de C. G. Jung, Vol. Vlll, Ed. 2. Petrópolis: Vozes, 1986

4. Jung CG. Analytic psychiatry principles. Obras completas de C. G.Jung, Vol. Xlll . Ed 2: Petrópolis: Vozes, 1985.

5. Anzieu D. The projective methods. 5Ed. Rio de Janeiro: Campus, 1989

6. Kupferman I. Localization of higher cognitive and affective function: the association cortices. In Principles of Neural Science. 3Ed. Connecticut: Appleton \& Lange, 1991;823-838.

7. Muszkat M. Consonant-vowel dichotic stimulation in patients with partial epilepsy. Thesis, Escola Paulista de Medicina. São Paulo, 1989.

8. Muszkat M. Study of hemispheric specialization in patients with partial epilepsy through tachistoscope test. Thesis - UNIFESP - Escola Paulista de Medicina. São Paulo, 1992.

9. Muszkat M, Vincenzo NS, Reami DO, Almeida CIR, Campos MI, Campos CJR. Hemispheric specialization in partial epilepsy - role of dichotic listening cv task and central audiological evaluation in the neuropsychological assessment. Arq Neuropsiquiatr 1991;49:384-391.

10. Popper RK, Eccles CJ. The self and its brain. Berlin: Springer-Verlag, 1977.

11. Siegel S. Non-parametric statistic for behavior science. São Paulo: McGraw-Hill, 1975.

12. Paim I. Psychopatology course. 10Ed. São Paulo: EPU, 1986

13. Friedman HE. Speech hesitation pauses as markers for mood disorders in stroke patients? J. Clin. Psychiatry 1991;52:140.

14. Friedman HE. Speech pause and diagnosis. J Clin Psychiatry 1991b;52:181.

15. Binnie CD, Kastelejn-Nolst Trenité DGA, Smith AM, Wilkins AJ. Interactions of epileptiformes EEG discharges and cognition. Epilepsy Res 1987;1:239-245.

16. Blaxtom TA, Bookheimer SW. Retrieval inhibition in anomia. Brain \& Language 1993;44:221-237.

17. Hermann BP, Sidenberg M, Haltiner A, Wyler AR. Adequacy of language function and verbal memory performance in unilateral temporal lobe epilepsy. Cortex 1992;28:423-433.

18. Howell R A, Saling MS, Bradley DC, Berkovic SF. Interictal language fluency in temporal lobe epilepsy. Cortex 1994;30:469-478,

19. Mayeux R, Brandt JP, Rosen J, Benson DF. Interictal memory and language impairment in temporal lobe epilepsy. Neurology 1980;30:120-125.

20. Cauthen RN. Verbal fluency: normative data. J Clin Psychol 1978;34:126129.

21. Heller W. Neuropsychological mechanisms of individual differences in emotion, personality and arousal. Neuropsychology 1993;4:476-489.

22. Sackeim HA, Greenberg MS, Weiman AL, Gur RC, Hungerbuhler JP, Geshwind N. Hemispheric asymmetry in the expression of positive and negative emotions: neurological evidence. Arch Neurol 1982;39:210-218.

23. Tucker DM. Lateral brain function, emotion and conceptualization. Psychol Bull 1981;89:19-46.

24. Charman DK. Do different personalities have different hemispheric asymmetries? A brief communiqué of an initial experiment. Cortex 1979;15:655-657.

25. Smith DB, Craft RB, Collins J, Mattson RH, Cramer JA. Behavioral characteristics of epilepsy patients compared with normal control. Epilepsia1986;27:760-768.

26. Amaducci L, Sorbi S, Albanese A. Choline-acetil-transferase (ChAT) activity differs in right and left human temporal lobes. Neurology 1981;31:799-805.

27. Herzog AG, Russel V, Vaitukaitis JL, Geshwind N. Neuroendocrine dysfunction in temporal lobe epilepsy. Arch Neur 1982;39:133-135.

28. Bear MD, Fedio P. Quantitative analysis of interictal behavior in temporal-lobe epilepsy. Arch Neurol 1977;34:454-467.

29. Fedio P, Martin AL. Ideative-emotive behavioral characteristics of patients following left or right temporal lobectomy. Epilepsia 1983;24:117-130.

30. Sergent J. Furtive incursions into bicameral minds. Brain 1990;113:537-568.

31. Sperry RW. Some effect of disconnecting the cerebral hemispheres. Science 1982;217:1223-1226.

32. Collard ME, Lesser RP, Luders H. Four dichotic speech tests before and after temporal lobectomy. Ear Hearing 1986;7:363-369.

33. Mazzuchi A, Parma M. Responses to dichotic listening in temporal epileptic with and without lesions. Cortex 1978;14:381-390. 